\title{
TESTS ON CONDUCTED ELECTRICAL NOISE ON A STORAGE RING DC-DC CONVERTER CABINET
}

\author{
JA Carwardine $-2 / 22 / 94$
}

\section{Summary}

Electrical noise is produced by switching transients in the power supply converters which excite resonances formed by stray capacitance and cable inductance. This noise is present not only on the load cables, but also on ground cables of the magnet and of the converter cabinet. Since there will eventually be a large number of cabinets running at one time, tests were carried out to characterize the noise and to investigate possible techniques for reducing the levels.

The tests were carried out on the test girder and converter cabinet set up in 412 area. There were four magnets installed on the girder - two $0.5 \mathrm{~m}$ quadrupoles, a $0.8 \mathrm{~m}$ quadrupole, and a sextupole. These tests were carried out on one of the $0.5 \mathrm{~m}$ quadrupoles. It should be noted that with this setup, the raw dc power was supplied at around $70 \mathrm{~V}$. In the final configuration, a $0.5 \mathrm{~m}$ quad will be fed from a $40 \mathrm{~V}$ raw supply. Consequently, the switching transients observed during the tests are likely to be higher than will occur in reality.

Noise currents contain two main components: a low frequency component at around $50 \mathrm{kHz}$, and a higher frequency component at around $1 \mathrm{MHz}$. It is the latter component which is of primary concern. Currents measured on the dc load cables typically were around one ampere, while currents into the building ground system were only a few tens of milliamps.

Several methods were used to try reducing the noise currents, but only the addition of a series impedance (common mode choke) was successful - other methods either had no effect or increased the ground currents.

\section{Attempts to Reduce the Conducted Noise Levels}

The noise is generated by switching transients in the dc-dc converter which excite resonances between stray system capacitance and series inductances. The first order model would be a switch and series/parallel resonant circuit. In theory, it should be possible to "short out" the resonant circuit and eliminate the oscillations by applying a capacitor between the dc output and ground. The problem is that the resonant circuit is not formed by discrete components, rather by capacitance and inductance distributed around the entire physical system. Linked with this is the fact that "ground" is also distributed, has inductance and capacitance associated with it, and is part of the resonant circuit in some undefined way. Figure 1 shows possible current paths via load cables, the stray capacitance from magnet coil to ground and back through the building ground system. 


\section{DISCLAIMER}

This report was prepared as an account of work sponsored by an agency of the United States Government. Neither the United States Government nor any agency thereof, nor any of their employees, make any warranty, express or implied, or assumes any legal liability or responsibility for the accuracy, completeness, or usefulness of any information, apparatus, product, or process disclosed, or represents that its use would not infringe privately owned rights. Reference herein to any specific commercial product, process, or service by trade name, trademark, manufacturer, or otherwise does not necessarily constitute or imply its endorsement, recommendation, or favoring by the United States Government or any agency thereof. The views and opinions of authors expressed herein do not necessarily state or reflect those of the United States Government or any agency thereof. 


\section{DISCLAIMER}

Portions of this document may be illegible in electronic image products. Images are produced from the best available original document. 
Nevertheless attempts were made to filter the noise by connecting capacitors from the dc output to cubicle ground. In all cases, the ground currents increased when the capacitor was added - in some cases by a factor of five. Other attempts were made to reduce the noise currents by adding a low impedance from the magnet terminals to ground, since there is significant coupling between the magnet and ground at high frequencies.

Following the lack of success with shunting the noise, the only choice left was to try increasing the impedance of the series circuit by adding a choke to the output of the converter. In order to prevent saturation of the choke magnetic core by the large dc load current, a common mode (bifilar wound) choke was the obvious design choice.

\section{Test Choke Design}

The choke must be designed to present a series impedance which is large relative to the impedance of the overall noise circuit. The choke must also be capable of handling $400 \mathrm{~A}$ dc.

Several large steel tape-wound toroids were available for the test. Since their performance at $1 \mathrm{MHz}$ was not known, some experimentation was required. A 1-micron tape-wound core was chosen. Ten turns wound around this toroid had a measured impedance of around $600 \mathrm{ohms}$ at $1 \mathrm{MHz}$. The final choke was created by winding two ten-turn coils around the toroid, each having 50 strands of $18 \mathrm{awg}$ wire to handle the dc current.

The choke impedance was measured for various frequencies up to $5 \mathrm{MHz}$. With the coils in parallel (common mode), the impedance was around $1000 \mathrm{ohms}$ at $1 \mathrm{MHz}$ and $600 \mathrm{ohms}$ at $2 \mathrm{MHz}$, while with the two coils connected in series an impedance of only $14 \mathrm{ohms}$ was measured at $1 \mathrm{MHz}$.

In order to verify that the choke would withstand the thermal losses, $150 \mathrm{~A}$ was passed through each coil for a period of 50 minutes. A temperature rise of only $30 \mathrm{deg} C$ was observed.

The design of a production choke would most likely be different from the design chosen for these tests. The use of tape-wound cores is generally expensive compared to other options (e.g. ferrites), and in the case of the quadrupole supplies, the production unit must be capable of handling up to $460 \mathrm{~A}$ continuously, possibly warranting water cooling. Since correctors would be required on all converter supplies, and since there are several different current ratings, there may be different choke designs for the different types of converter.

\section{Baseline Tests without the Common Mode Choke}

Measurements were carried out to determine the baseline noise levels. Two current toroids were used to make measurements: A Fisher F35-1 EMC current probe, and a 
Pierson 3100 current probe. The two probes were cross calibrated by simultaneously measuring the same waveform. Manufacturer's performance (in the case of the Pierson probe) and previous calibration (in the case of the Fisher probe) were found to be consistent with the relative amplitudes observed on the two traces.

Conducted noise levels were measured at several locations: (1) the common mode current on the load cables to the magnet, (2) current on the converter cabinet ground cable, (3) current from the girder to building ground, (4) current from the raw supply to building ground (overall power system ground). Locations (3) and (4) provide the best indication of the conducted emissions from the power system. These are shown schematically in Figure 2.

Figure 3 shows waveforms measured in the above four locations when one quadrupole supply is energized at its nominal operating level of $370 \mathrm{~A}$. For these cases, the other three magnets on the girder were connected to their respective power supplies (see note later). Two significant components can be identified in the waveforms: a $1 \mathrm{MHz}$ transient, and a slower $50 \mathrm{KHz}$ component. Table 1 gives estimated amplitudes for the two frequency components at each of the four locations.

Table 1

\begin{tabular}{|l|c|c|}
\hline \multicolumn{1}{|c|}{ Location } & 1MHz component & $50 \mathrm{KHz}$ component \\
\hline (1) load cables & $1 \mathrm{~A} \mathrm{p}-\mathrm{p}$ & $250 \mathrm{~mA} \mathrm{p}-\mathrm{p}$ \\
\hline (2) converter cabinet ground & $125 \mathrm{~mA} \mathrm{p}-\mathrm{p}$ & $50 \mathrm{~mA} \mathrm{p}-\mathrm{p}$ \\
\hline (3) girder to building ground & $58 \mathrm{~mA} \mathrm{p}-\mathrm{p}$ & $20 \mathrm{~mA} \mathrm{p}-\mathrm{p}$ \\
\hline (4) power system to ground & $38 \mathrm{~mA} \mathrm{p}-\mathrm{p}$ & $5 \mathrm{~mA} \mathrm{p}-\mathrm{p}$ \\
\hline
\end{tabular}

\section{Tests with the Common Mode Choke}

Once the baseline current levels were measured, the common mode choke was installed in the load cables of the supply and the tests were repeated. Figure 4 show the waveforms obtained. It can be seen that the $1 \mathrm{MHz}$ transient has virtually disappeared into the noise floor. Amplitudes for the low frequency component are hardly affected (see Table 2 below).

Table 2

\begin{tabular}{|l|c|}
\hline \multicolumn{1}{|c|}{ Location } & $50 \mathrm{KHz}$ component \\
\hline (1) load cables & $100 \mathrm{~mA} \mathrm{p}-\mathrm{p}$ \\
\hline (2) converter cabinet ground & $50 \mathrm{~mA} \mathrm{p}-\mathrm{p}$ \\
\hline (3) girder to building ground & $20 \mathrm{~mA} \mathrm{p}-\mathrm{p}$ \\
\hline (4) power system to ground & $5 \mathrm{~mA} \mathrm{p}-\mathrm{p}$ \\
\hline
\end{tabular}




\section{Conclusions}

Noise currents are introduced into the building ground system by switching transients in the converter cabinet system. These are relatively small given the dc current delivered to the magnet, but may become a problem once a number of cabinets are operated together.

The incorporation of the common mode choke into the dc output of the converter supply attenuates the high frequency components of the noise to background levels.

It should be noted that a full implementation of the common mode choke to the storage ring converters would require a separate choke for each individual converter approximately 1400 units.

Note about multiple magnet connections on a common girder

The tests described above were conducted with a total of four magnets connected to their respective converter supplies in the same cubicle. Only the quadrupole supply was operated. Other tests were carried out where only one magnet was connected to its power supply; in these cases noise currents from one converter were conducted onto the dc cables of the other magnets. Figure 4 shows two paths taken by the noise currents. Path 1 shows how noise currents flow on another magnet's power cables. Path 2 is the simpler case for a single magnet. In practice, all possible paths will carry some current where the amplitude is determined by relative path impedances. The effect on multiple magnets/cabinets needs to be addressed later when there are two cabinets/girders available since the possibility exists that noise currents could flow between cabinets via dc cables and girder ground connections.

\section{IA Carwardine}




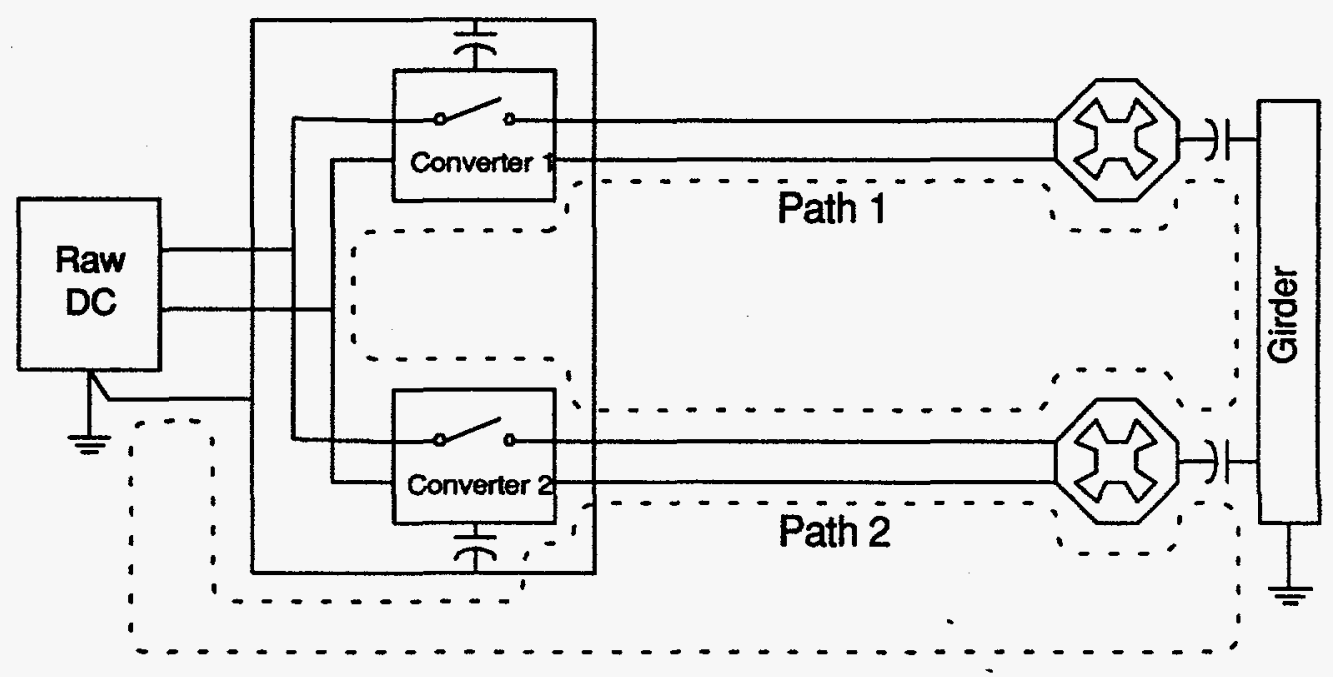

Figure 1 - Primary Noise Current Paths

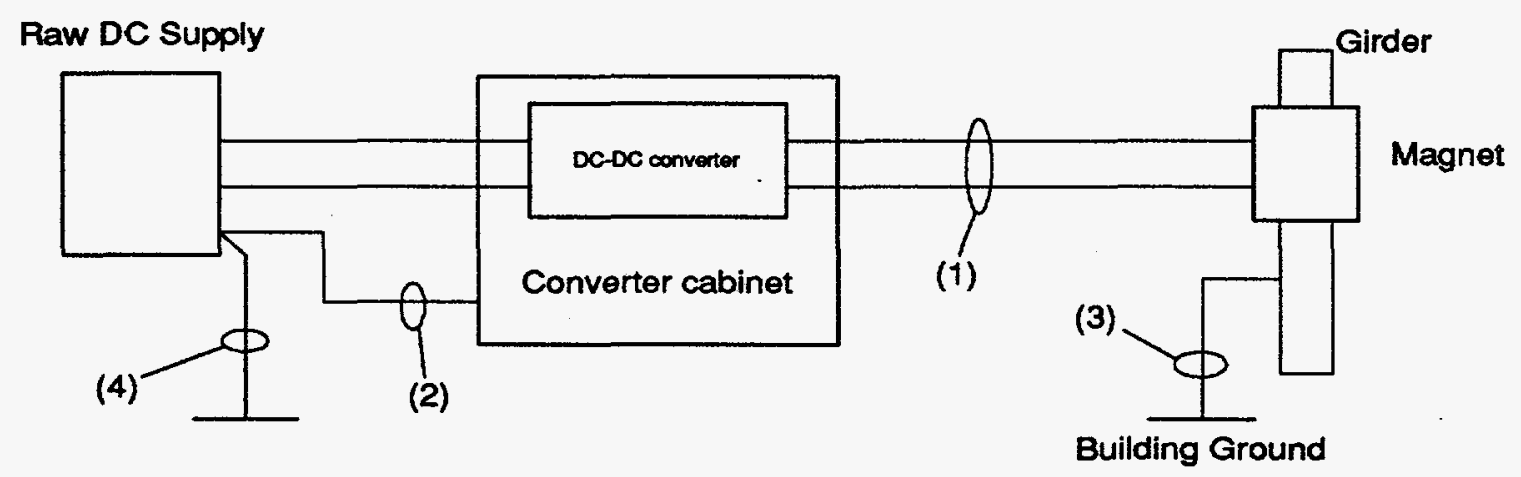

Figure 2 - Location of Current Toroids During Tests 

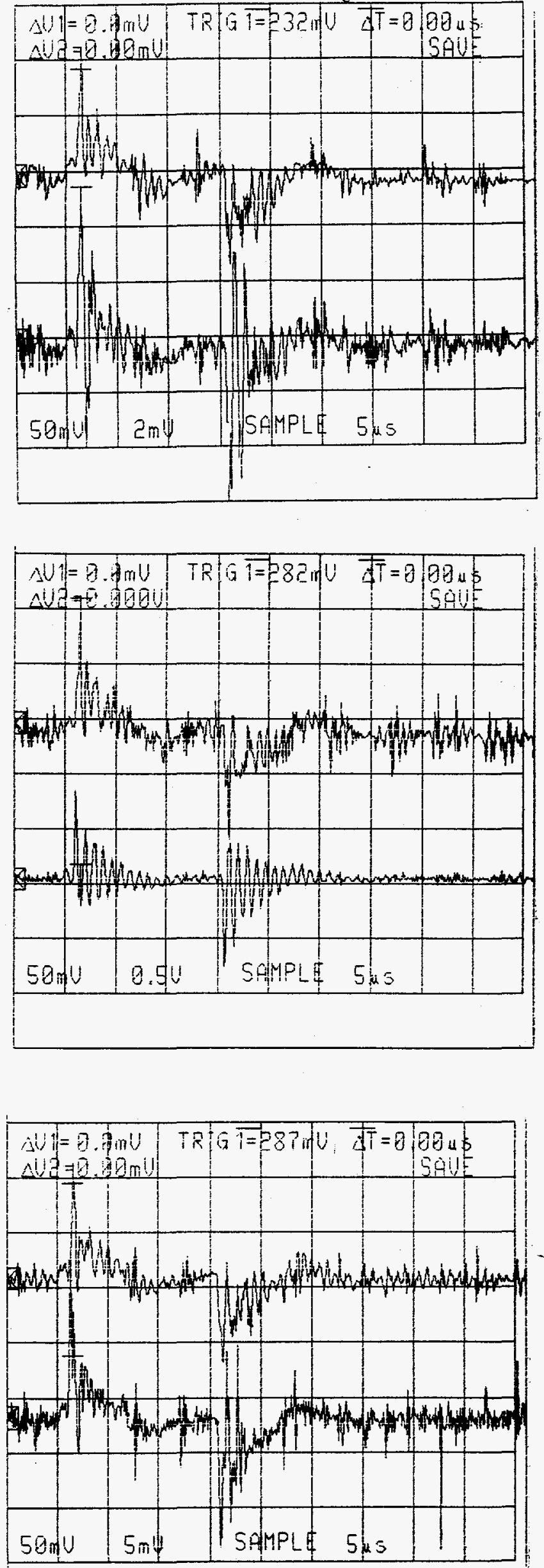

(a)

Converter Ground - 50mA / Division

Power System Ground - 8mA / Division

(b)

Converter Ground - 50mA / Division

C.M. Load Current - 500mA / DIvision

(c)

Converter Ground - 50mA / Division

Girder-Building Ground - 20mA / Division 

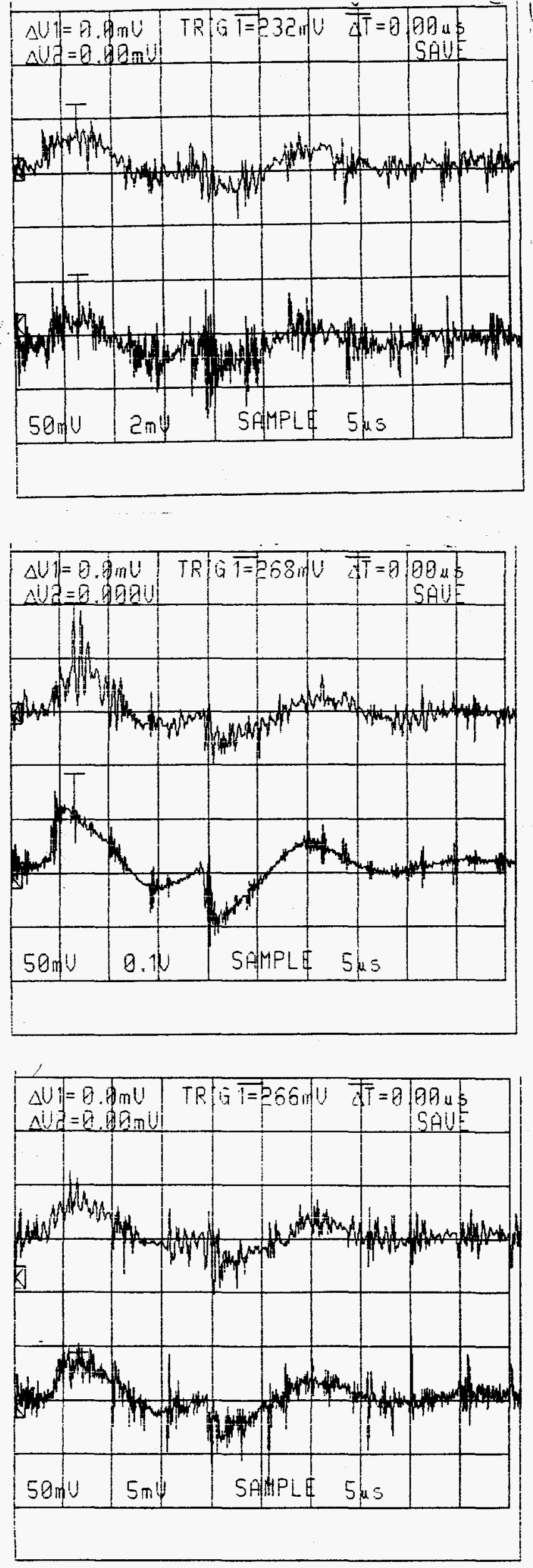

(a)

Converter Ground - 50mA / Division

Power System Ground - 8mA / Division

(b)

Converter Ground - 50mA / Division

C.M. Load Current - 500mA / DIvision

(c) 